Article

\title{
Enhancing Meso Level Research in Sustainability Science—Challenges and Research Needs
}

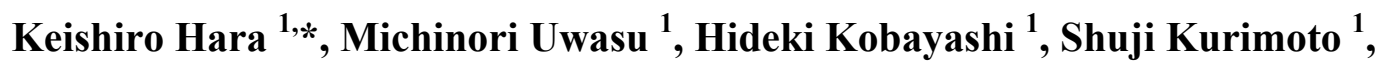
Shinsuke Yamanaka ${ }^{2}$, Yoshiyuki Shimoda ${ }^{2}$ and Yasushi Umeda ${ }^{2}$

1 Center for Environmental Innovation Design for Sustainability, Osaka University, 2-1 Yamada-oka, Suita, 565-0871 Osaka, Japan; E-Mails: uwasu@ceids.osaka-u.ac.jp (M.U.); kobayashi@ceids.osaka-u.ac.jp (H.K.); kurimoto@ceids.osaka-u.ac.jp (S.K.)

2 Graduate School of Engineering, Osaka University, 2-1 Yamada-oka, Suita, 565-0871 Osaka, Japan; E-Mails: yamanaka@see.eng.osaka-u.ac.jp (S.Y.); shimoda@see.eng.osaka-u.ac.jp (Y.S.); umeda@mech.eng.osaka-u.ac.jp (Y.U.)

* Author to whom correspondence should be addressed; E-Mail: hara@ceids.osaka-u.ac.jp; Tel.: +81-6-6879-4150; Fax: +81-6875-6271.

Received: 8 June 2012; in revised form: 23 July 2012 / Accepted: 30 July 2012 /

Published: 15 August 2012

\begin{abstract}
Growing numbers of promising visions of the future and scenarios that may lead toward building sustainable societies are being developed. At the same time, advanced technologies and research seeds that could increase the likelihood of achieving such visions are also being rigorously conceived. Even so, we face challenges and barriers in achieving these visions due to large gaps between individual technology seeds and shared visions. In this paper we propose a "vision-meso-seeds" model as a practical framework for addressing sustainability transition and demonstrate meso level research whose primary aim is to design a matching of promising seeds at the micro level and societal visions at the macro level, facilitating an achievement of the set visions with quantified targets. In particular we highlight the importance of matching various strategies and measures derived from the top-down (vision-oriented) approach and bottom-up (seeds-oriented) approach in the meso level research. We argue that the meso level research shall constitute one of the emerging core fields in sustainability science and suggest that accumulation of knowledge through case studies be needed to enhance and verify theory, specific methods and approach necessary for advancing the meso level research in the context of sustainability science.
\end{abstract}


Keywords: bottom-up-approach; technology seeds; top-down approach; vision-meso-seeds model

\section{Introduction}

The human race faces a number of complex challenges at multiple levels that hinder our transition to sustainable societies [1]. Sustainability science plays crucial roles in dealing with these challenges, providing future visions, and exploring complex, dynamic interactions that occur among the global system (e.g., climate, resources, ecosystems), social system (e.g., politics, economy, socio-technical systems) and human system (e.g., life style, health, values and norms) through interdisciplinary approaches [2-5].

The essential features of sustainability science have been established based on past studies. Kajikawa (2008), for example, highlights the basic components of sustainability science, including goal setting, forecasting, backcasting, indicator measurement, and causal chain analysis [6]. In fact, an increasing number of studies are addressing essential approaches and promising tools in sustainability science such as visioning and future scenario approaches, multilateral (sustainability) indicator systems and knowledge structuring [7-9]. In particular, vision and scenario making, among others, is an important field where sustainability science is and will be contributing. Indeed, a number of scenario studies have been developed to tackle a variety of environmental and sustainability problems, while scenario typologies and techniques have made advances as well [10,11]. For example, the backcasting approach, which is highly solution-driven, is expected to play an important role in specifying appropriate measures, strategies and roadmaps, both from technological and policy viewpoints, in dealing with shared goals leading to sustainability [12].

On the other hand, technological advancement and innovations have been rigorously addressed in the field of sustainability. Some technological innovations have come from curiosity-driven research, while others are made possible by societal demands and policy intervention [13-15]. Indeed, an increasing number of promising technologies, such as various materials and devices for EV (electric vehicles) and heatpumps, that might help us deal with environmental problems and promote sustainable development, have been invented through rigorous research activities at universities, research institutes and corporations.

It appears that these available advanced technologies, coupled with the increasing number of future visions with specific targets and a variety of measures derived from backcasting scenarios, might enable us to make the transition to sustainability. However, we still find it difficult to make the societal transitions that will allow us to achieve our mid- and long-term future goals. The transition to a sustainable society requires integrating multiple levels of innovations that may lead to drastic changes not only in technology, but also in industry and society at large. We argue that practical discussions about the appropriate implementation of advanced technologies in society and the connecting them with social targets, thereby making the transition to sustainability in the real world, have been lacking. In particular, the research framework and systems in place to help us bridge available research seeds (or technologies) to shared visions at multiple levels are still weak. 
In this paper, we propose a "vision-meso-seeds" model for use in sustainability science as a flexible, but useful framework to address the linkages between technology and research seeds at the micro level, such as EV and thermoelectric conversion technology, and visions with specific quantitative targets at the macro level. By citing examples of Japan's national visions such as sound material-cycle society and low-carbon society, we first explain barriers and challenges that hinder the achievement of visions, particularly highlighting the disconnection between available seeds at the micro level and national visions at the macro level. We then demonstrate what we mean by "meso level" research in the context of vision-meso-seeds model, whose primary function is to explore gaps between individual technology seeds and societal visions and to fill those gaps and inconsistencies. In particular, we emphasize the importance of matching various strategies and measures obtained from a top-down (vision oriented) approach and concrete packages of technologies derived from a bottom-up (seeds oriented) approach in meso level research. Thus we highlight the importance of enhancing meso level research.

Finally we suggest that meso level research be developed as a practical framework to understand the complexities and dynamism of the interactions between technology seeds and society at large in the process of sustainability transition. In this regard, theory, practicality and methodologies that are unique to such meso level research should be verified and enhanced by accumulating relevant knowledge through case studies at various scales.

\section{Disconnection between Seeds and Visions-A Challenge in Sustainability Science}

In pursuing sustainable development, creating and sharing visions for desirable societies is essential in directing relevant practices and activities. Scenario making can tell us what pathways and consequences society can possibly take while providing alternative viable options to achieve sustainability. Because of this, visioning and future scenario studies are considered to be distinct fields in sustainability science. Its unique roles have been recognized in policy discussions such as those regarding climate change $[16,17]$. Nonetheless, practical perspectives on how to bring options to fruition and measures derived from scenarios have not been fully discussed, let alone systematized frameworks to address such practical perspectives. Though studies increasingly address various approaches to explore sustainability transition and societal innovations [18-22], few studies discuss the gaps and possible inconsistencies that might occur between available seeds and visions with specific and quantitative targets, such as $70 \%$ GHG (Greenhouse gas) reduction by 2050 , and provide a systemic framework to effectively address this aspect. Yamaguchi et al. (2007) studied a transition management model supporting a designed transition toward a sustainable low-carbon society based on a backcasting approach, in which the model was applied to the commercial sector building stock of Osaka city, Japan [23]. The study addressed the necessity of innovations at multiple levels, including technology, industry and society, and identified key components that would drive the transition from a socio-technical system viewpoint. However, the study did not fully address systemic understanding and practical methods to facilitate such multiple levels of innovations by integrating visions at macro level and key technology seeds at micro level.

In this paper, we specifically focus on the gaps between technology seeds and visions as a challenge. We argue that inventing advanced technologies and promoting technological innovations alone will 
not inevitably lead to a transition to sustainability because there are gaps between available science and technology seeds and sustainability visions. A systemic and practical framework for discussing how to bring about transitions that lead to realization of the visions is needed in sustainability science. Using the examples of a "Sound material-cycle society" (SMS) and a "Low-carbon society", both of which constitute core pillars of Japan's visions towards sustainability [24], we first explain possible challenges in achieving such visions, which provides a rational for proposing a new research framework in this paper.

\subsection{The Case of Japan's Visions towards a Sustainable Society}

Recent economic growth, particularly that observed in Asian countries, coupled with rapid urbanization and industrialization, has caused a variety of challenges, such as resource overconsumption, massive stocks of materials in urban areas, environmental pollution and societal inequality. Notably, the massive material consumption associated with economic activities poses alarming threats to sustainability on a global scale. Given the situation, Japan has set forth a policy to promote a "sound material-cycle society" as an important pillar of its sustainability strategy.

SMS is defined in its policy document as a society in which the consumption of natural resources will be conserved and the environmental load will be reduced to the greatest extent possible. This will be done by preventing or reducing the generation of wastes through the cyclical use of products that become circulative resources, and by ensuring proper disposal of circulative resources not put into cyclical use. To achieve these goals, the government proposed a Fundamental Plan for Establishing a Sound Material-Cycle Society in 2003 [25].

Future scenarios and social visions for the SMS concept have been studied [26,27]. In the meantime, there are a variety of promising technologies, evaluation methods and initiatives that have been developed at micro levels, all of which individually have the potential to contribute to realizing the societal vision. Table 1 illustrates an example of components (or individual seeds) of available technologies, institutional designs and initiatives that have been discussed in SMS-related research fields. These are the available seeds related to both industrial systems and urban/rural systems for the SMS [28]. As the table shows, a variety of seeds and knowledge are already available and even practiced at various levels. Many advanced technology seeds are being invented and knowledge is being produced that should theoretically help achieve the SMS vision through the daily research activities of universities, research institutes and companies.

Notably, SMS policy goals with quantitative values have been set as well. The Fundamental Plan for Establishing a Sound Material-Cycle Society enacted by the government of Japan in 2003 introduced comprehensive quantitative indicators based on material flow accounts at the national level [25]. Three indicators, resource productivity, recycling ratio and amount of final disposal, were chosen with specific quantitative goals for the period between 2000 and 2010. For instance, resource productivity, which addresses the ratio of GDP to direct material input, should increase about $40 \%$, from approximately 280,000 yen/ton to 390,000 yen/ton between 2000 and 2010 . A study analyzed the main factors that have contributed to increased resource productivity, such as changes in the structure of demand (i.e., the magnitude of the demand for a particular set of goods and services relative to total demand), improvement in recycling, and a steady decline in final demand for construction during the 
study period [29]. These factors turn out to have contributed to meeting the target set for resource productivity as a consequence, but were not intended or predicted from the beginning. No clear idea or strategies existed for the best ways to mobilize available seeds (e.g., technologies, initiatives), as indicated in Table 1, to be able to achieve set goals. Many unpredicted changes in socio-economic conditions and utilization of individual seeds within the markets during the periods could have also affected the performance of the effort.

This example clearly demonstrates the complexity and disconnection (distance) between available seeds and goals set in the pursuit of a vision. While having specific goals and research seeds (e.g., technologies), it might not be easy to find out pathways to realize the visions by linking both sides. In the following section, we specify examples of likely challenges that may explain the disconnection and distance between seeds and set visions.

Table 1. Examples of technology seeds, institutional designs and initiatives related to Japan's sound material-cycle society.

\begin{tabular}{ll}
\hline & Available or potential seeds and measures \\
\hline Technologies & Eco-material, Bio-refinery, Environmentally compatible polymer materials, Material \\
and seeds & $\begin{array}{l}\text { processing technologies, Separation and sorting technologies, Combustion } \\
\text { technologies, Water reuse and recycling technologies, Membrane technologies, }\end{array}$ \\
& Bio remediation, etc. \\
Institutional & Recycling fee, Various taxes, Deposit system, Standardization, PPP (Polluter Pay \\
design/policy & Principle), EPR (Extended Producer's Responsibility), WEEE (Waste Electrical and \\
measures & Electronic Equipment Directive), RoHS (Restriction of Hazardous Substances), etc. \\
Concepts, & Zero-emission, Eco Industrial Park (EIP), Cleaner production, Dematerialization, \\
initiatives and & Industrial ecology, Eco-Design, DfE (Design for environment), Inverse manufacturing, \\
projects & Sustainable consumption, Land and ecosystem conservations, Urban metabolism, etc. \\
\hline
\end{tabular}

\subsection{Specific Barriers and Challenges in Achieving Sustainability Visions}

In terms of complex relationships between individual technology seeds and visions, we highlight some of the critical challenges derived from the cases of "sound material-cycle society" and "low-carbon society" in Japan. Such challenges include, but are not limited to:

1) Complexity in terms of spatiotemporal boundaries

2) Barriers in synthesizing and optimizing available science and technology seeds

3) Tradeoffs and synergies among applied technologies and visions

4) Time lags and uncertainties in technology saturation in markets

5) Time lags in efficacy of technology applications in society

6) Uncertainty in the institutional design and responsive behavior of the private sector and consumers

7) Uncertainty about the private sector and consumers' capacity to learn and adapt

8) Insufficient societal verification/assessment systems

The first item addresses the aspect of physical boundaries and time scales. As noted in Section 2.1, the quantitative policy targets between 2000 and 2010 (i.e., resource productivity, recycling ratio, final disposal amounts) at national level were set by the government in 2003 to promote the pursuit of SMS. 
There are a variety of options and initiatives available, such as eco-industrial parks (EIP). Such individual initiatives should have contributed to an increase in the recycling ratio at the national level while they individually have specific physical scales and boundaries. However, it is not clear which seeds (i.e., technologies, practices and initiatives) should work best in achieving national goals and what spatial boundaries of each practices and initiatives are most effective. Identifying the optimal spatial level of recycling practices (industrial plant, city or region) and the best combinations of such practices at different spatial levels will also be no simple task when designing strategies and roadmaps with time towards the vision. Indeed, structured knowledge was not available when the quantitative national targets were set in the case of Japan's SMS policy.

The second item deals with science and technology seeds and addresses the necessity of synthesizing and optimizing promising, but usually scattered and unstructured, seeds. Traditionally, scientific activities have started with the objective of understanding some unexplained feature, and thus analysis has been the primary focus of most research. Accordingly, scientific disciplines tend to become increasingly narrow and specialized as their analyses became more detailed in their focuses [30]. For example, universities' main priority has not been to systematize or synthesize knowledge developed within them beyond the boundaries of their various disciplines. Conversely, sustainability science requires that such synthesizing capability be enhanced in order to achieve a sustainable society or tackle sustainability problems. Practices that overview such vast knowledge and the seeds are still very limited, while synthesis and optimization of available technology seeds in line with specific purposes require a completely different approach.

The third item is about possible tradeoffs or synergies that might surface among available applications of technology seeds. While there are a variety of available technologies to be applied for achieving SMS and low-carbon society, simple combinations of available technologies will not ensure the realization of societal goals, mainly because synergies and tradeoffs, which are likely to be more difficult to identify, might cause unintended consequences. Selecting the best combination of technology seeds to ensure the optimal level is not an easy task at seeds level. Further, conflicts between visions bring another sort of tradeoff. For example, electric vehicles and smart grids, thought to be key devices for achieving low-carbon societies, might deplete rare metals, thus conflicting with resource sustainability. This issue is also related to conflicts among different sectors such as industries. In fact, these examples represent systems' complexity, given that there are many systems' interactions in society. Thus, it is also necessary to crosscut perspectives beyond sectors and between policy visions in dealing with sustainability issues. Though many kinds of tradeoffs and synergies can be imagined, there has not been enough research done that looks at this aspect beyond traditional discipline boundaries, especially from the stance of realizing sustainability visions.

The fourth and fifth items are mainly about time lags that exist in the application of technologies. Technologies should be applied or deployed in societies in the form of products (e.g., solar panels) and various forms of systems (e.g., smart grids). In practice, products and systems are usually chosen by consumers in markets. There will be time lags between when technologies are applied and their diffusion or saturation in the market, even if such technologies and products are chosen. Studies of the diffusion of individual technologies consistently find patterns where the rate of technology adoption rises slowly at first, speeds up and then levels off as market saturation approaches [31], showing a certain time needed for diffusion following such a pattern. It is also possible that time lags exist 
between when technologies appear in markets and the time when their efficacy becomes visible. Thus, it is crucial to take time lags that should be expected into consideration when planning applications of science and technologies.

The sixth and seventh items have to do with a variety of "uncertainties" that can be anticipated. We highlight, among other issues, uncertainty about behavior in the private sector and consumers' ability to adapt to changing environments. When policy measures, which might have been identified from backcasting scenarios, are applied to induce behavioral changes, policy makers must assume that how consumers will react and to what extent they will be capable of adjusting to the induced changes cannot be known precisely beforehand. For example, there is a possibility that purchasing of energy efficient devices are not going to be facilitated as anticipated, due possibly to increasing energy related expenses for consumers, which stems from the imposition of relevant environmental policies. Another example is that the private sector, including industries that face severe competition in the global market, tends to have fewer incentives to reduce greenhouse gases (GHGs), and so the extent of future private sector efforts to make reductions is subject to large uncertainty. The behavior of such stakeholders is not easily controlled, which makes it harder to identify specific policy measures that will be most effective. Another type of uncertainty is that seen in the political scheme. Even if good policy measures are designed, they are often subject to uncertainty in political movements and governance. This aspect also should be taken into account in sustainability transition.

Finally, the eighth item highlights the lack of verification or appraisal systems in society. Verification in this context means an evaluation scheme embedded in society for testing whether implemented policies and applied technologies deal appropriately with specific problems or meet societal needs. Such a verification or appraisal system is essential in directing societies toward envisioned sustainability. For instance, "technology assessment" with stakeholders' participation is becoming more widely recognized as an important factor in enhancing public involvement to mobilize the science and technology used to sustain our society when benefits and risks are shared by stakeholders [32]. Similarly, building sustainable societies necessitates maintaining a persistent and reflexive verification scheme over time and the participation of the various stakeholders.

These examples demonstrate that producing and applying advanced technologies alone will not bring about the achievement societal goals. Nor will the simple combination of available science and technology seeds lead to shared goals. Fujimoto et al. (2008) discuss the mismatch that exists between technology-driven (bottom-up) approaches and vision-driven (top-down) approaches in the context of building a low-carbon society [33]. While there is now an array of accessible technologies and measures for tackling climate change, simple combinations of them will not ensure that we meet societal goals such as a $70 \%$ reduction of $\mathrm{CO}_{2}$ emissions by 2050 . Even when promising measures and time frameworks for their implementation are identified using backcasting, $\mathrm{CO}_{2}$ emission reduction might be subject to a number of uncertainties (challenges 6 and 7 above). Even though measures are proposed by sectors (e.g., industry, households), many of which were derived from backcasting scenarios, simple combinations of such arrays of measures will not ensure the achievement of vision. With energy efficient products made of promising technologies, total GHG emissions could actually increase if consumers use them more; there could be rebound effects. As energy related products could interact with one another in the market in a complex and dynamic manner, how much impact energy 
efficient products will have in reducing energy consumption and associated $\mathrm{CO}_{2}$ emissions in society when they come to market is neither clear nor self-evident [34].

In summary, exploring such dynamism and complexities in terms of technology-society relationships and bridging the mismatches of various strategies and measures, including both technologies and policies, derived from bottom-up and top-down approaches constitutes a core challenge that ought to be overcome in pursuit of sustainability transition. This shows why the systemic framework of "meso" level research, which aims to design the linkages between element seeds at micro level and societal goals at macro level, is indispensable.

\section{Meso Level Research in a Vision-Meso-Seeds Framework}

In order to overcome the challenges noted earlier, we propose a new framework featuring meso level research in a three-level model (Figure 1). We incorporate the vision level (e.g., sound material-cycle society), a meso level and the seeds level (e.g., enabling technologies such as photo-voltaic materials). In this framework, "vision" addresses policy directions and shared images of a sustainable society, which are desired and pursued by the people who live in the society. "Seeds" primarily refers to element technologies, proper applications and combinations of which shall increase the likelihood of realizing visions. Based on the understanding of the complex relationships between systems that sustainability science has explored, we need to effectively systematize and mobilize technology seeds to materialize societal visions at macro level. We have learned, however, that it is impossible to relate such seeds to visions directly due mainly to the distance between them. Technologies, a variety of societal systems, and institutions across various sectors must all be taken into consideration to deploy promising seeds into the real world, carefully preventing deployment side effects such as rebound phenomena [35]. It is therefore crucial to look between the individual seeds and societal visions, in the meso level, to make the necessary connections and designs.

Figure 1. Vision-meso-seeds model framework.

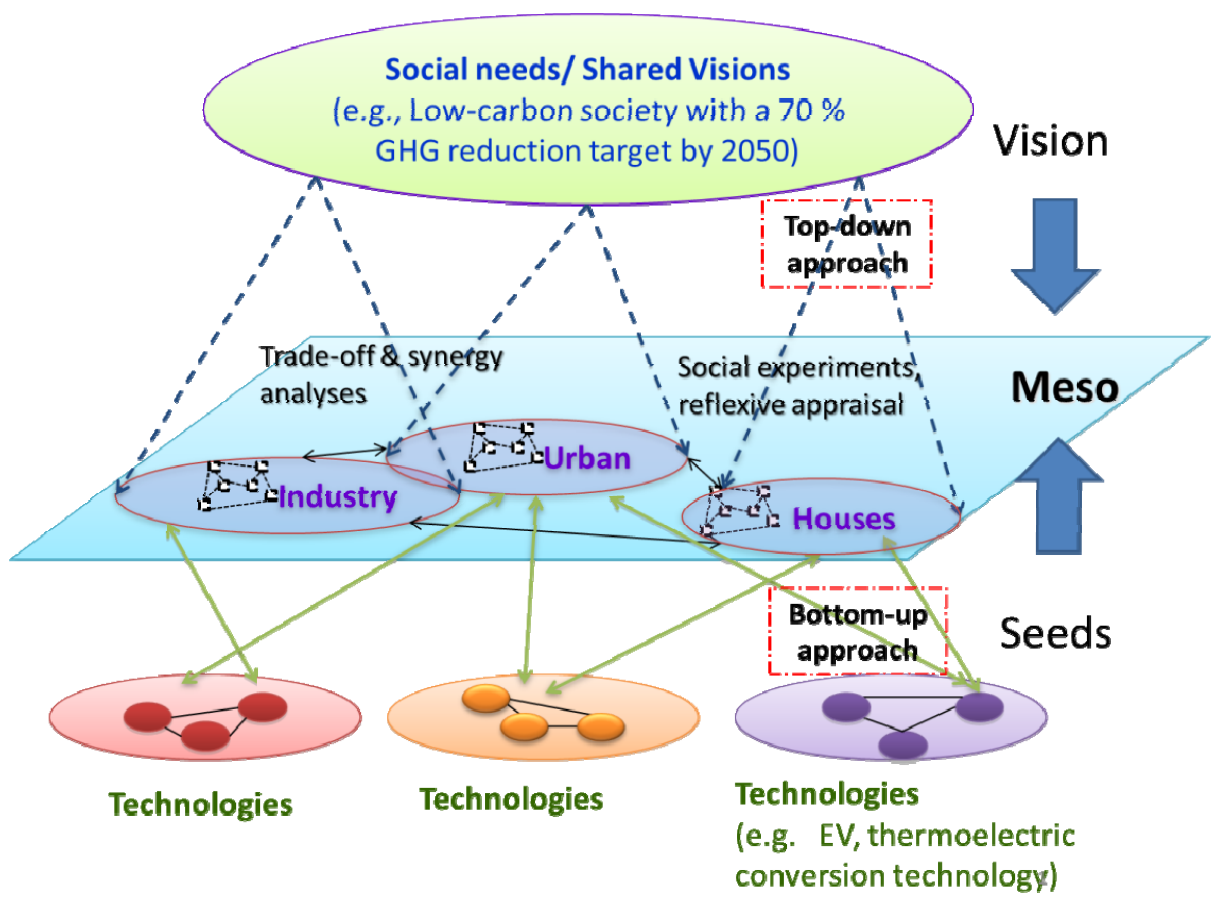


As a framework to systematize the meso level research, we propose the classification of meso level research into (1) top-down (vision-oriented) approaches and (2) bottom-up (seeds-oriented) approaches. Top-down approach allows us to breakdown the vision into sector-specific measures with such methods as backcasting scenarios and to identify available and promising measures in terms of technologies and institutional designs. The bottom-up approach aims to identify the best combinations of available technology seeds and addresses possible diffusions of such packages of seeds in the society and markets. A careful matching of measures from top-down approach and technology packages obtained from bottom-up approaches, avoiding inconsistencies between them, is the key area which the meso level research should examine, which will allow us to overcome the challenges listed in Section 2.2. At the same time, it is also the role for the meso level research to look into the matching or structuring measures specified by sectors (e.g., industry, urban sector, households, etc.) to ensure the optimal level or consistency of applied measures in society at large (Figure 1) beyond the sectionalism. In this regards, both vertical matching (top-down and bottom-up approach) as well as horizontal matching (consistency or optimal level) among sectors constitute the most important function of the meso level research. The following lists some essential functions and components that meso level research should take into consideration based upon the top-down and bottom-up approaches.

- Top-down approach (vision-oriented):

This approach mainly specifies strategies and tangible measures from the "vision" side. The primary focus of this approach is to identify macro-level strategies by sectors such as industries and houses (i.e., lifestyle) and specify roadmaps for achieving the set visions. In this regards, scenario approach, such as backcasting, is of vital importance. It is indeed essential to identify promising measures, including both technologies and institutional designs based on specific visions and backcasting scenario, along with roadmaps and time frameworks associated with them. It is also important to look into various uncertainties and complexities, such as people's behavioral responses in markets, while determining reasonable time lags, such as the time needed for promising technologies to become saturated in markets after policy implementations. Top-down approach is also aimed at specifying vision-oriented or sustainability-driven R \& D strategies or prioritized research domains for technology development that aligns with societal values and norms [36].

- Bottom-up approach (seeds-oriented approach):

This approach primarily addresses the transition towards sustainability from the technology and seeds side. The primary concerns of this approach include, but are not limited to, systematizing, synthesizing and structuring available seeds; bringing available technologies together with supporting systems or institutions that are specified in line with visions and prioritized measures, such as standardization; multidimensional assessment of the sustainability of available technologies; analyses of tradeoffs and synergies among available technology seeds; identifying conflicts and side effects that may arise from the application of technologies in society and markets; and promoting technology steps such as upgrades, up- or downscaling, replacements and substitutions, combinations and coupling, networking and linking.

Further, these research components represented by both top-down and bottom-up approach should be effectively supported by social experiments and transition facilitation involving stakeholder 
participation. Implementing research results and technology seeds in the real world is of vital importance in realizing future visions. Having an appraisal system that can be used over time is also indispensable in verifying the appropriateness of technologies, policy measures and roadmaps to societal transition/transformation. Various stakeholders should participate in the system over time so their changing priorities and experiences can be integrated. Consistent collaboration between science and society in sustainability science is essential as a means to test and measure the effects and impacts of actions taken and to make necessary corrections over time [37]. This requires input from various actors in society. Accountability and consensus building exercises are also essential in operationalizing the meso level research, particularly considering the abduction nature of sustainability science [30]. It is also indispensable that there will be an impact on policies relevant to sustainability particularly in the process of meso level research where various stakeholders, including policy makers, are actively involved.

Table 2. Examples of components and approach indispensable for meso level research (Essential perspectives to look into both with top-down approach and bottom-up approach).

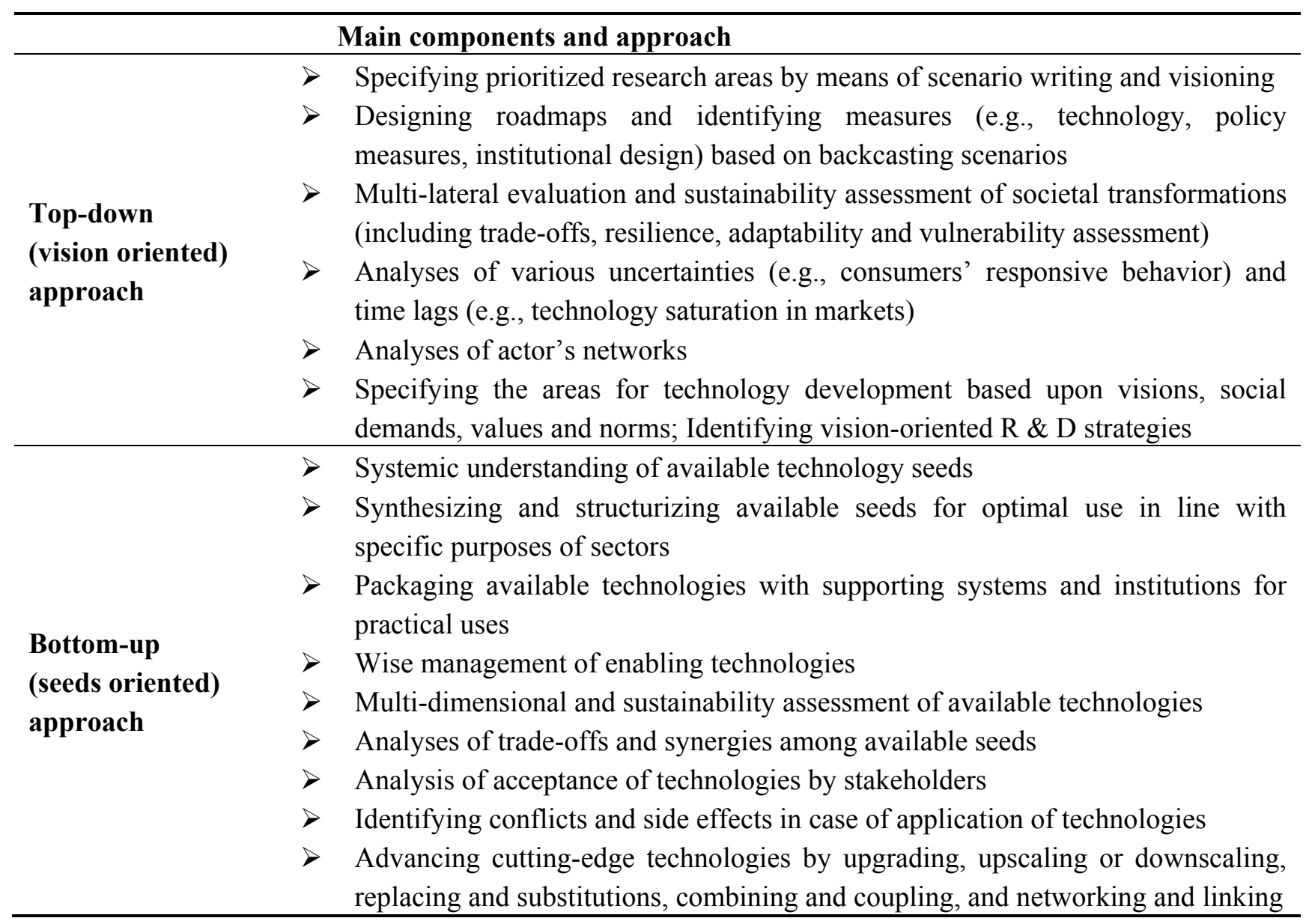

Table 2 illustrates the examples of specific approaches and methods that might be indispensable for meso level research areas in the category of top-down and bottom-up approaches. Some of the items listed as components of meso level research have so far been addressed individually or separately in sustainability science, but there is no existing systematic research framework or approach for meso level research that fits with the vision-meso-seeds framework. The most important aspect of the 
framework is to consider the matching strategies and knowledge made available by top-down approach and bottom-up approach, avoiding the inconsistency that might occur if each approach is carried out individually, while facilitating societal transitions in a practical way. Thus the function of meso level research in nature encompasses different approaches including synthesis, analysis and structuring of knowledge, design and actions.

To discuss an example of meso level in a rather concrete manner, we hereby illustrate a case of "utilization of waste heats in urban and industrial sectors" which, among others, is now considered to be a promising and key measure and research field drawing attention in realizing a low-carbon society in Japan. Indeed, it is estimated that vast amount of heats are wasted in urban areas and industrial sectors [38]. On the other hand, there have been rigorous studies and advancement of such promising technologies as thermoelectric conversion elements, waste heat recovery technologies and thermal conductive materials as available and promising seeds, all of which may contribute to facilitate the utilization of waste heats. These technologies are being developed to the level where application of the technologies in the real world is almost feasible. The question is now how these technologies (seeds) can be best synthesized and mobilized to realize the option (i.e., utilization of vast amount of waste heats in urban and industrial sectors), eventually facilitating energy savings and a low-carbon society (vision). Even if this option of waste heat utilization as part of energy saving measures to facilitate low-carbon society is derived from backcasting scenario, ensuring this option in the real world requires a careful analysis and design by means of meso level research. For example, the potential for GHG emission reduction by adopting this option in such sectors as urban areas (e.g., waste heat from cars, incinerators, air conditioners, etc.) are not clearly identified. Assessment of such potential depending on the sectors is thus needed as a part of top-down approach, along with an evaluation of the specific contribution of this option (i.e., utilization of waste heat) to the total energy saving or GHG emission reduction target as a vision. Such assessment and analysis shall be also needed and this assessment requires both seeds and vision sides. Also, as far as thermoelectric conversion elements as technology seeds are concerned, integrated evaluation is needed to analyze the risk of resource depletion or conflict arising from the use of rare metals in thermoelectric conversion elements; the potential risks of side effects such as the environmental load associated with applying the technology in society; and the life cycle environmental loads that mass production of thermoelectric conversion elements will carry. This is an important dimension which refers to the trade-off and optimization in applying available technology seeds. Other examples of meso level research (particularly top-down approach) include, but are not limited to, predictions of diffusion patterns for technologies such as thermoelectric conversion elements; identifying milestones for R \& D promotions in view of technology applications and their diffusion in society; provision of business models, such as recycling systems. On the other hand, examples of bottom-up approach are; choosing the most appropriate technologies for particular uses and purposes (e.g., waste heats from cars), optimized packaging of available technologies for particular uses given the different characteristic and natures of each technology, multi-lateral evaluation of such technologies looking into both merits, risks and trade-offs, just to name a few. These components constitute an example of meso level research beyond the boundary of discipline and sectors, and the meso level research particularly intends to focus on matching the promising technology seeds and vision sides in a systemic manner and designing linkages both sides, instead of carrying out 
such analyses and evaluations individually. Equally importantly, social experiments with stakeholder participation are indispensable as far as the verification and implementation are concerned over time.

We highlight in this paper that arriving at a linear solution and determining measures to promote sustainability using a backcasting approach does not ensure that we have found the correct pathway for transitioning to sustainability. Carefully tailored measures that consider the viewpoints of both sides, available technology seeds and visions, will facilitate the societal transitions leading to the visions. As yet, knowledge and methods peculiar to the framework of meso level research which we proposed is still insufficient. Enhancement and verification of the proposed meso level research in the course of advancing sustainability science must continue, as records of actual practices accumulate and various types of case studies at all scales are examined. It is equally important to design proper institutions and governance that allow the effective promotion of meso level research. While various stakeholders such as policy makers shall be involved in the process of meso level research, the role of universities as a hub of knowledge would be of critical importance in coordinating the research activities, mobilizing people who are from different fields and disciplines, and streamlining individual research activities (e.g., top-down and bottom-up approaches) in an integrated manner.

\section{Conclusions-Future Prospects and Research Needs}

In this paper, we first explained the distance between available promising technology seeds and societal visions, and discussed the concept of meso level research which focuses on linking individual technology seeds and societal visions with specific targets in the pursuit of realizing a sustainable society. We discussed a systemic framework and the essence of meso level research in a vision-meso-seeds model describing the matching of top-down and bottom-up approaches; i.e., avoiding possible inconsistencies between rather abstract strategies derived from top-down approach and usually very concrete technological measures/packages based upon the available individual technology seeds. Meso level research indeed addresses dynamic and complex interactions of technology seeds and society at large and it shall help understand the connection of distant visions and available technologies in a systemic manner, eventually contributing to the achievement of set visions. We argue that accumulation of knowledge through case studies as well as societal experiments including stakeholders is indispensable to enhance the new framework and to develop methodologies and approaches peculiar to the meso level research. Though we demonstrated the importance of meso level research by presenting the cases of Japan's societal vision (i.e., SMS and low-carbon society), the knowledge we could gain might vary depending on the cases and examples, in terms of scale (e.g., internationally pursued visions) and time-framework (short-term goals or long-term goals). Thus, carrying out various types of case studies is of vital importance as the first step to enhance the concept and framework of vision-meso-seeds model in sustainability science. This new framework should also be examined from the viewpoints of usefulness, practicality, etc., by having comparative analyses together with other relevant theories and existing models.

We also argue that such meso level research should be increasingly practiced at the university level. In fact, practices to overview potential research and technology seeds at the university level are still very weak. It will become increasingly more important for knowledge hubs, such as universities, to provide collective knowledge through a systematic understanding of individual research seeds in order 
to cope with complex sustainability problems and social experiments. To this end, involving meso level research, which requires highly interdisciplinary and strategic collaboration beyond the conventional academic disciplines, as an integral part of overall research activities will be an essential and practical option. Let alone, collaboration among stakeholders including universities is of vital importance, as well.

For future studies and challenges it would also be indispensable to look into the conditions with which to effectively stimulate smooth cooperation and interdisciplinary collaborations among researchers, in particular those working on individual technologies at the micro level (e.g., engineer) and those involved in the visions side (e.g., economist). It is essential to nurture and incentivize researchers who could play a key role in meso level research with broad perspectives and in-depth knowledge for technologies and their applications in society. It is also crucial to strengthen the cooperation among a variety of stakeholders, including universities, industries, government and citizens, for meso level research to be carried out in a successful manner. In this regard, it will be indispensable to study how best universities are able to cooperate with societies to implement meso level research to foster social innovations towards sustainability.

\section{References}

1. Kates, R.W.; Parris, T.M. Long-term trends and a sustainability transition. Proc. Natl. Acad. Sci. USA 2003, 100, 8062-8067.

2. Komiyama, H.; Takeuchi, K. Sustainability science: Building a new discipline. Sustain. Sci. 2006, 1, 1-6.

3. Clark, W.C.; Dickson, N.M. Sustainability science: The emerging research program. Proc. Natl. Acad. Sci. USA 2003, 100, 8059-8061.

4. Kates, R.W. What kind of a science is sustainability science? Proc. Natl. Acad. Sci. USA 2011, 108, 19449-19450.

5. Kates, R.W.; Clark, W.C.; Corell, R.; Hall, J.M.; Jaeger, C.C.; Lowe, I.; McCarthy, J.J.; Schellnhuber, H.J.; Bolin, B.; Dickson, N.M.; et al. Sustainability science. Science 2001, 292, 641-642.

6. Kajikawa, Y. Research core and framework of sustainability science. Sustain. Sci. 2008, 3, 215-239.

7. Jäger, J.; Rothman, D.; Anastasi, C.; Kartha, S.; van Notten, P. Scenario Development and Analysis, GEO Resource Book: A Training Manual on Integrated Environmental Assessment and Reporting; UNEP and IISD; Winnipeg, Canada, 2007.

8. Hara, K.; Uwasu, M.; Yabar, H.; Zhang, H. Sustainability assessment with time-series scores: A case study of Chinese provinces. Sustain. Sci. 2009, 4, 81-97.

9. Kumazawa, T.; Saito, O.; Kozaki, K.; Matsui, T.; Mizoguchi, R. Toward knowledge structuring of sustainability science based on ontology engineering. Sustain. Sci. 2009, 4: 99-116.

10. Borjeson, L.; Hojer, M.; Dreborg, K.H.; Ekvall, T.; Finnveden, G. Scenario types and techniques: Towards a user's guide. Futures 2006, 38, 723-739.

11. Van Notten, P.; Rotmans, J.; van Asselt, M.; Rothman, D. An updated scenario typology. Futures 2003, 35, 423-443. 
12. Quist, J.; Vergragt, P. Past and future of backcasting: The shift to stakeholder participation and a proposal for a methodological framework. Futures 2006, 38, 1027-1045.

13. Popp, D. Lessons from patents: Using patents to measure technological change in environmental models. Ecol. Econ. 2005, 54, 209-226.

14. Foxon, T.J. Inducing Innovation for a Low-Carbon Future: Drivers, Barriers and Policies; The Carbon Trust: London, UK, 2003.

15. Fischer, C.; Parry, I.W.H.; Pizer, W.A. Instrument choice for environmental protection when technological innovation is endogenous. J. Environ. Econ. Manag. 2003, 45, 523-545.

16. Intergovernmental Panel on Climate Change. Climate Change 2007, Synthesis Report. Contribution of Working Groups I, II, III to the Fourth Assessment Report of the Intergovernmental Panel on Climate Change (IPCC); Publisher: Geneva, Switzerland, 2007.

17. Fujino, J. Development of Japan Low Carbon Society Scenarios toward 2050. Paper Presented at the COP11 and COP/MOP1 Side Event: Global Challenges Toward Low-Carbon Economy, Montreal, Canada, Day December 2005.

18. Foxon, T.J. A coevolutionary framework for analysing a transition to a sustainable low carbon economy. Ecol. Econ. 2011, 70, 2258-2267.

19. Kemp, R.; Rotmans, J. The Management of the Coevolution of Technical, Environmental and Social Systems. In Towards Environmental Innovation Systems; Weber, M., Hemmelskamp, J., Eds.; Springer Verlag; Berlin, Germany, 2005.

20. Loorbach, D. Transition Management: New Mode of Governance for Sustainable Development; International Books; Utrecht, The Netherlands, 2007.

21. Grin, J.; Rotmans, J.; Schot, J.; Geels, F.; Loorbach, D. Transitions to Sustainable Development: New Directions in the Study of Long Term Transformative Change; Routledge; London, UK and New York, NY, USA, 2010.

22. Hoogma, R.; Kemp, R.; Schot, J.; Truffer, B. Experimenting for Sustainable Transport. The Approach of Strategic Niche Management; EF\&N Spon: London, UK, 2002.

23. Yamaguchi, Y.; Takahashi, Y.; Hara, K.; Yabar, H.; Saito, O.; Morioka, T. Transition Management Model with Back-casting Approach: Case Studies of the Development of a Low Carbon Society. In Proceedings of the 5th International Symposium on Environmentally Conscious Design and Inverse Manufacturing (EcoDesign2007), Tokyo, Japan, 10-13 December 2007; pp. 1-9.

24. Government of Japan. Becoming a Leading Environmental Nation Strategy in the 21st Century - Japan's Strategy for a Sustainable Society; GOJ: Tokyo, Japan, 2007.

25. Ministry of Environment. Fundamental Plan for Establishing a Sound Material-Cycle Society; MOE: Tokyo, Japan, 2003.

26. Hashimoto, S.; Osako, M.; Abe, N.; Inaba, R.; Tasaki, T.; Nansai, K.; Fujii, M.; Matsuhashi, K.; Moriguchi, Y. Scenarios planning on resource/waste flows and resource recycling/waste management system in the near future (in Japanese). J. Jpn. Soc. Civ. Eng. 2009, Division G 65, 44-56.

27. Hara, K.; Saito, O.; Yabar, H.; Yamaguchi, Y.; Morioka, T. Building future scenarios toward resource-circulating society-Case study in yangtze river delta. Proceedings of the 35th Annual Meeting of Environmental Systems Research 2007, 35, 123-128. 
28. Morioka, T.; Hanaki, K.; Moriguchi, Y. Establishing a Resource-Circulating Society in Asia: Challenges and Opportunities; United Nations University Press: Tokyo, Japan, 2011.

29. Hashimoto, S.; Matsui, S.; Matsuno, Y.; Nansai, K.; Murakami, S.; Moriguchi, Y. What factors have changed Japanese resource productivity? A decomposition analysis for 1995-2002. J. Ind. Ecol. 2008, 12, 657-668.

30. Yoshikawa, H. Synthesiology as sustainability science. Sustain. Sci. 2008, 3, 169-170.

31. Popp, D. International innovation and diffusion of air pollution control technologies: The effects of NOX and SO2 regulation in the U.S., Japan, and Germany. J. Environ. Econ. Manag. 2006, $51,46-71$.

32. Hirakawa, H. Science and Technology Communication. In Sustainability Science: $A$ Multidisciplinary Approach; Komiyama, H., Takeuchi, K., Shiroyama, H., Mino, T., Eds.; United Nations University Press: Tokyo, Japan, 2011; pp. 204-219.

33. Fujimoto, J.; Umeda, Y.; Kondoh, S.; Matsumoto, M.; Masui, K.; Kimura, F. Concept of "meso-level" that provides a link between macro and micro levels. Proceedings of EcoDesign Japan Symposium A 12-2. CD-ROM, Tokyo, Japan, 2008, in Japanese.

34. Huppes, G.; Ishikawa, M. A framework for quantified eco-efficiency analysis. J. Ind. Ecol. 2005, 9, 25-41.

35. Umeda, Y. The needs of meso level research for sustainability research and agenda of research and education of CEIDS. In Proceedings of the EcoDesign2011-7th International Symposium on Environmentally Conscious Design and Inverse Manufacturing, Kyoto, Japan, 30 November-2 December 2011; pp. 563-567.

36. Kobayashi, H.; Kato, M.; Maezawa, Y.; Sano, K. An R\&D management framework for eco-technology. Sustainability 2011, 3, 1282-1301.

37. Yoshikawa, H. Science and Technology for Society. In Sustainability Science: $A$ Multidisciplinary Approach; Komiyama, H., Takeuchi, K., Shiroyama, H., Mino, T., Eds.; United Nations University Press: Tokyo, Japan, 2011; pp. 256-271.

38. Ayres, B.; Ayres, E. Crossing the Energy Divide: Moving from Fossil Fuel Dependence to a Clean-Energy Future; Pearson Prentice Hall: Upper Saddle River, NJ, USA, 2009.

(C) 2012 by the authors; licensee MDPI, Basel, Switzerland. This article is an open access article distributed under the terms and conditions of the Creative Commons Attribution license (http://creativecommons.org/licenses/by/3.0/). 